\title{
Exteroceptive factors and pregnancy block in the Mongolian gerbil, Meriones unguiculatus
}

\author{
M. L. Norris and C. E. Adams \\ Agricultural Research Council Institute of Animal Physiology, Animal Research Station, \\ 307 Huntingdon Road, Cambridge CB3 OJQ, U.K.
}

\begin{abstract}
Summary. A series of experiments based on 150 newly mated, uni- and multi-parous Mongolian gerbils provided no evidence for the existence of pregnancy blocking due to a strange male effect. The reduced level of fertility observed was attributed to stressful factors at critical times in the pregnancy. Treatment with 10 i.u. PMSG on the day following mating interrupted pregnancy and the majority of females mated again within 4 days.
\end{abstract}

\section{Introduction}

Pregnancy block induced by a strange male, the so-called 'Bruce effect' was first demonstrated in the mouse (Bruce, 1959, 1960a, b) and, subsequently, in the deermouse, Peromyscus maniculatus (Eleftheriou, Bronson \& Zarrow, 1962; Bronson \& Eleftheriou, 1963), and the voles, Microtus agrestis (Clulow \& Clarke, 1968) and Microtus pennsylvanicus (Clulow \& Langford, 1971). The effect is caused by male urinary pheromones (Parkes \& Bruce, 1962; Dominic, 1966a, b). Chapman, Desjardins \& Whitten (1970) suggested that pituitary gonadotrophin release in the newly mated female in response to the 'strange male' pheromone is the pregnancy blocking agent. Hoppe \& Whitten (1972) showed that administration of PMSG was able to block pregnancy in newly mated rats and mice.

The present experiments were designed to evaluate the susceptibility of the Mongolian gerbil, a cricetid rodent, to exteroceptive factors, including the presence of a strange male, and also to determine whether treatment with PMSG would block pregnancy.

\section{Materials and Methods}

A total of 150 mated female Mongolian gerbils, from our own colony, including 90 uniparae and 60 multiparae, was used. All of the animals were kept in polypropylene boxes, measuring $38 \times$ $25 \times 18 \mathrm{~cm}$ (type RC2: North Kent Plastic Cages Ltd, Dartford, Kent), under conditions as described elsewhere (Norris \& Adams, 1972a). Vaginal smears were taken by lavage between 09:00 and 10:00 h, and upon confirmation of mating (Day 1) 120 females were allocated to 1 of 6 experiments, each containing 20 animals, as follows.

Experiments 1 and 2. Multiparous females were either placed with a 'strange' male for $48 \mathrm{~h}$ (Exp. 1) or were moved into freshly cleaned boxes for $48 \mathrm{~h}$ (Exp. 2) and then returned to their original box and male; their mean ages were $235 \pm 20$ days and $203 \pm 12$ days respectively. Vaginal smears were taken for 2 days after mating.

Experiments 3 and 4 . Older multiparae, mean age $378 \pm 25$ days, and younger uniparae, mean age $181 \pm 12$ days, were placed with a 'strange' male for the duration of the preimplantation period ( 8 days) and then returned to the original box and male on Day 9 . The 
boxes containing the 'strange' males were not cleaned out for a period of at least 1 month before test. Vaginal smears were taken for 2 days after mating.

Experiments 5 and 6 . Uniparae were either placed in freshly cleaned boxes and then returned to their original box and male on Day 9 (Exp. 5), or left with their stud male throughout (Exp. 6); their mean ages were $242 \pm 9$ days and $207 \pm 13$ days respectively. Whenever the movement of females led to fighting which did not end within $15 \mathrm{~min}$, the females were anaesthetized, as described by Norris \& Adams (1972b), and then rejoined.

Experiment 7. In this experiment 15 uniparae, mean age $167 \pm 20$ days, were injected s.c. with 10 i.u. PMSG (Serum gonadotrophin B.P.: Paines \& Byrne Ltd, Greenford, Middlesex) in $0.2 \mathrm{ml}$ sterile $0.9 \%(\mathrm{w} / \mathrm{v}) \mathrm{NaCl}$ on Day 2 between 09:00 and 10:00 h, whilst 15 other uniparae, mean age $182 \pm 22$ days, were similarly treated but with vehicle only. Vaginal smears were taken up to and including Day 6, or to the time of second mating.

Females to Exps 1 to 7 were checked for littering 24 to 26 days p.c. The results were analysed using $\chi^{2}$ tests.

\section{Results}

Agonistic behaviour. Of the 100 females moved in the course of the present experiments, 29 ( 6 from Exp. 1, 6 from Exp. 2, 7 from Exp. 3, 6 from Exp. 4 and 4 from Exp. 5) showed some degree of agonistic behaviour. Eighteen of the incidents occurred when a newly mated female was introduced into the cage containing the 'strange' male, and 11 when replaced with the stud male. In 14 cases aggression subsided within $15 \mathrm{~min}$. Of the 15 females which were anaesthetized 11 were successfully paired whilst the other 4 remained aggressive and could not be rejoined. In these cases the stud male was removed and the female left alone for 26 days.

Vaginal smears. Of the 80 females (Exps 1-4) from which smears were taken on Days 2 and 3, $76(95 \%)$ showed a uniform smear pattern, consisting of leucocytes with a few small, rounded, nucleate epithelial cells and a total absence of cornified elements. Two females from Exp. 2 had smears in which epithelial cells were dominant and in 1 female from Exp. 3 cornified cells predominated. One female from Exp. 3 had a cornified smear with spermatozoa present after 1 day with the 'strange' male but did not litter. All 15 PMSG-treated females in Exp. 7 had leucocytes and epithelial cells present in the vaginal smears on the morning of Day 2 but within 2 days $12(80 \%)$ females showed a fully cornified smear. During the test period $9(60 \%)$ females had spermatozoa in the smear within 4 days of being given PMSG. In all 15 controls the smear consisted of leucocytes and epithelial cells throughout the entire test period.

Table 1. Outcome of pregnancy in Mongolian gerbils subjected to exteroceptive stimulation or treatment with PMSG post coitum

\begin{tabular}{|c|c|c|c|c|c|}
\hline Exp. & Treatment & $\begin{array}{c}\text { No. of } ९ Q \\
\text { observed }\end{array}$ & Parity & $\begin{array}{c}\text { Mean } \pm \text { s.e.m. } \\
\text { age at } \\
\text { mating (days) }\end{array}$ & $\begin{array}{c}\text { No. of } \$ Q \\
\text { littering }(\%)\end{array}$ \\
\hline 1 & 48 h with 'strange' $\delta$ ' & 20 & Multiparous & $235 \pm 20$ & $12(60)$ \\
\hline 2 & Moved to clean box for $48 \mathrm{~h}$ & 20 & Multiparous & $203 \pm 12$ & $11(55)$ \\
\hline 3 & 9 days with 'strange' $\delta$ & 20 & Multiparous & $378 \pm 25$ & $9(45)$ \\
\hline 4 & Kept in heavily soiled box & 20 & Uniparous & $181 \pm 12$ & $10(50)$ \\
\hline 5 & Moved to fresh box till Day 9 & 20 & Uniparous & $242 \pm 9$ & $9(45)$ \\
\hline 6 & No movement & 20 & Uniparous & $207 \pm 13$ & $17(85)$ \\
\hline 7 & 10 i.u. PMSG, Day 2 & 15 & Uniparous & $167 \pm 20$ & $1(7)$ \\
\hline- & Control & 15 & Uniparous & $182 \pm 22$ & $10(67)$ \\
\hline
\end{tabular}

Experiments 1 versus 2 and 3 versus 4, N.S.; Exp. 5 versus 6, $P<0.05 ;$ Exp. 7 versus control, $P<0.01$. 
Pregnancy. Exposing multiparous females to a 'strange' male for $48 \mathrm{~h}$ had no significant effect on the proportion littering (see Table 1, Exps 1 and 2), and when older multiparae and younger uniparous females were paired with a 'strange' male in a heavily soiled box up to Day 9 $45 \%$ to $50 \%$ littered, which was similar to that in Exp. 1 (Table 1, Exps 1-4). Females left undisturbed following mating reproduced significantly better than females of similar age subjected to movement (Exps 5 and 6$)\left(\chi^{2}=5 \cdot 38 ; P<0.05\right)$. Following treatment with PMSG (Exp. 7) only 2 females littered, including 1 as a result of a second mating immediately after PMSG treatment; she produced a litter of 18 young, of which 15 were born alive. Ten (67\%) of the control females littered as a result of the preinjection mating; the difference in the proportion of experimental and control females littering was significant $\left(\chi^{2}=7.36 ; P<0.01\right)$.

\section{Discussion}

Our results provide no evidence for the existence of functional 'strange male' pheromone(s) capable of effecting a pregnancy block in the Mongolian gerbil. Nevertheless, the possibility remains that the young female mating for the first time may be susceptible to the influence of a 'strange' male. In the laboratory mouse an increasing resistance to pregnancy block in older females has been reported (Chipman \& Fox, 1966). Because the Mongolian gerbil produces very little urine (Schwentker, 1963), we attempted to compensate for this fact by using heavily soiled boxes in conjunction with a longer period of female exposure. However, it is still possible that insufficient pheromone-bearing urine was present to have any effect on the female. There is also evidence for the presence of an extra-urinary pheromone in the ventral sebaceous gland in the Mongolian gerbil (Thiessen, Blum \& Lindzey, 1969; Thiessen et al., 1974), but the present results suggest this is not important in relation to pregnancy blocking; a scent marking response has been associated with the gland (Thiessen et al., 1969).

In experimental females, which were handled and moved to different cages post partum, the proportion littering was significantly reduced compared with that of untreated animals, $85 \%$ of which littered, which is consistent with earlier reports (Marston \& Chang, 1965; Norris \& Adams, 1971). There are 3 factors, all considered stressful, which could be acting either alone or in combination to affect pregnancy, i.e. handling and moving the female to a new environment, fighting, and exposure to ether. It is notable that in the case of the most fertile group (Exp. 6) none of these factors was operative, whilst they were all present to a greater or lesser degree in the other groups in Exps 1-5. Accounts of the behaviour patterns that precede fighting have been given by Nyby, Thiessen \& Wallace (1970) and of aggressive behaviour relative to age and sexual experience at pairing by Norris \& Adams (1972c).

It appears, therefore, that the gerbil is sensitive, especially during the first third of pregnancy, to non-pheromonal, exteroceptive factor(s). In the deermouse, factors such as disturbance are known to block pregnancy in non-lactating females (Eleftheriou et al., 1962). Extreme sensitivity of the gerbil to external stimuli is indicated by its proneness to seizures in response to noise, movement or handling (Thiessen, Lindzey \& Friend, 1968). Relative to body weight the gerbil's adrenals are among the largest of any animal species (Nickerson, 1971); however, the significance of adrenal function for reproduction is unknown in this species.

The results obtained with PMSG clearly indicate that early administration of this gonadotrophin prevents implantation in the gerbil. The possible mechanisms of action in rats and mice have been discussed by Hoppe \& Whitten (1972). The fact that a high proportion of our PMSGtreated gerbils became oestrous and mated is indicative of an increase in oestrogen levels. The newly mated gerbil, therefore, seems to behave like the laboratory rat, showing a negative effect with a 'strange' male (Dominic, 1969) and a positive blocking reaction in response to gonadotrophin treatment (Hoppe \& Whitten, 1972), but unlike the golden hamster, in which PMSG is ineffective in blocking pregnancy (Greenwald, cited by Hoppe \& Whitten, 1972). 


\section{References}

Bruce, H.M. (1959) An exteroceptive block to pregnancy in the mouse. Nature, London, 184, 105.

Bruce, H.M. (1960a) A block to pregnancy in the mouse caused by the proximity of strange males. J. Reprod. Fert. 1, 96-103.

Bruce, H.M. (1960b) Further observations on the pregnancy block in mice caused by the proximity of strange males. J. Reprod. Fert. 1, 311-312.

Bronson, F.H. \& Eleftheriou, B.E. (1963) Influence of strange males on implantation in the deermouse. Gen. comp. Endocr. 3, 515.

Chapman, V.M., Desjardins, C. \& Whitten, W.K. (1970) Pregnancy block in mice: changes in pituitary $\mathbf{L H}$ and LTH and plasma progestin levels. J. Reprod. Fert. 21, 333-337.

Chipman, R.K. \& Fox, K.A. (1966) Factors in pregnancy blocking: age and reproductive background of females: numbers of strange males. J. Reprod. Fert. 12, 399-403.

Clulow, F.V. \& Clarke, J.R. (1968) Pregnancy-block in Microtus agrestis, an induced ovulator. Nature, Lond. 219, 511.

Clulow, F.V. \& Langford, P.E. (1971) Pregnancy-block in the meadow vole, Microtus pennsylvanicus. $J$. Reprod. Fert. 24, 275-277.

Dominic, C.J. (1966a) Observations on the reproductive pheromones of mice. I. Source. J. Reprod. Fert. 11, 407-414.

Dominic, C.J. (1966b) Observations on the reproductive pheromones of mice. II. Neuro-endocrine mechanisms involved in the olfactory block to pregnancy. $J$. Reprod. Fert. 11, 415-421.

Dominic, C.J. (1969) Pheromonal regulation of mammalian reproduction. Indian Biologist, 1, 1-18.

Eleftheriou, B.E., Bronson, F.H. \& Zarrow, M.X. (1962) Interaction of olfactory and other environmental stimuli on implantation in the deermouse. Science, N.Y. 137, 764.

Hoppe, P.C. \& Whitten, W.K. (1972) Pregnancy block: imitation by administered gonadotrophin. Biol. Reprod. 7, 254-259.
Marston, J.H. \& Chang, M.C. (1965) The breeding, management and reproductive physiology of the Mongolian gerbil, Meriones unguiculatus, Lab. Anim. Care 15, 34-48.

Nickerson, P.A. (1971) Fine structure of the Mongolian gerbil adrenal cortex. Anat. Rec. 171, 443-456.

Norris, M.L. \& Adams, C.E. (1971) Delayed implantation in the Mongolian gerbil, Meriones unguiculatus. J. Reprod. Fert. 27, 486-487.

Norris, M.L. \& Adams, C.E. (1972a) The growth of the Mongolian gerbil (Meriones unguiculatus) from birth to maturity. J. Zool., Lond., 166, 277-282.

Norris, M.L. \& Adams, C.E. (1972b) Suppression of aggressive behaviour in the Mongolian gerbil, Meriones unguiculatus. Lab. Anim. 6, 295-299.

Norris, M.L. \& Adams, C.E. (1972c) Aggressive behaviour and reproduction in the Mongolian gerbil, Meriones unguiculatus, relative to age and sexual experience at pairing. J. Reprod. Fert. 31, 447-450.

Nyby, J., Thiessen, D.D. \& Wallace, P. (1970) Social inhibition of territorial marking in the Mongolian gerbil (Meriones unguiculatus). Psychon. Sci. 21, $310-312$.

Parkes, A.S. \& Bruce, H.M. (1962) Pregnancy block in female mice placed in boxes soiled by males. $J$. Reprod. Fert. 4, 303-308.

Schwentker, V. (1963) The gerbil, a new laboratory animal. The Illinois Veterinarian, 6, 5-9.

Thiessen, D.D., Blum, S.L. \& Lindzey, G. (1969) A scent marking response associated with the ventral sebaceous gland of the Mongolian gerbil (Meriones unguiculatus). Anim. Behav. 18, 26-30.

Thiessen, D.D., Lindzey, G. \& Friend, H.C. (1968) Spontaneous seizures in the Mongolian gerbil (Meriones unguiculatus). Psychon. Sci. 11, 227228.

Thiessen, D.D., Regnier, F.E., Rice, M., Goodwin, M., Isaaks, N. \& Lawson, N. (1974) Identification of a ventral scent marking pheromone in the male Mongolian gerbil (Meriones unguiculatus). Science, N.Y. 184, 83-85. 